\title{
Effects of Surface Chemistry of Silica Particles on the Mechanical Properties of Silica Filled Styrene-Butadiene Rubber Systems
}

\author{
Fumito Yatsuyanagi, Nozomu Suzuki, Masayoshi Ito, ${ }^{\dagger}$ \\ and Hiroyuki KAIDOU* \\ Department of Chemistry, Faculty of Science, Science University of Tokyo, 1-3 Kagurazaka, \\ Shinjuku-ku, Tokyo 162-8601, Japan \\ ${ }^{*}$ Research \& Development Center, The Yokohama Rubber Co. Ltd., 2-1 Oiwake, \\ Hiratsuka, Kanagawa 254-8601, Japan
}

(Received November 6, 2001; Accepted March 30, 2002)

\begin{abstract}
The effects of surface chemistry of silica particles on the mechanical properties were studied for silica filled styrene-butadiene rubber (SBR) systems. The samples were prepared from different kinds of silicas and of silane coupling agents. The breakdown of the agglomerate formed by silica particles was successfully detected by transmission electron microscopy (TEM) observations when the strain was applied to silica filled vulcanizates. The degree of breakdown of the agglomerate of silica particles by the strain was more prominent in the larger one of which size was controlled by the number of silanol group per unit surface area of silica particles. The amount of entrapped rubber within the agglomerate seemed to be decreased with the decrease in the agglomerate size. Also, the initial agglomerate size and the change of agglomerate by the strain became small by the introduction of silane coupling agent, such as bis(3-triethoxysilylpropyl)tetrasulfane (TESPT). At a given degree of vulcanization, the initial modulus of silica filled vulcanizates was governed by the size of agglomerate formed by silica particles and the amount of entrapped rubber phase. On the other hand, at a larger strain, the tensile strength of the filled vulcanizates increased by the introduction of interfacial combination between silica particles and rubber matrix by TESPT. These results indicate that the stress-strain behavior of filled vulcanizate is affected by the agglomerate of the fillers and the interactions between filler and rubber matrix.

KEY WORDS Silica / Styrene-Butadiene Rubber / Silane Coupling Agent / Transmission Electron Microscopy (TEM) / Agglomerate / Mechanical Properties /
\end{abstract}

Silicas have been used as fillers for rubber reinforcement. ${ }^{1-3}$ However, the utilization of silica caused two serious problems. One was a bad processability, such as a lower dispersiblity of silica particles in rubber matrix and a high viscosity of silica filled unvulcanizates. ${ }^{2-8}$ The other one was a poor reinforcement, such as a low tensile strength, low abrasion resistance and so on, in comparison with carbon black filled rubber composites. ${ }^{1-8}$ The chemical environment of silica particle is quite different from that of carbon black due to the existence of silanol groups in the particles. Thus, the primary discussion on the properties of silica filled rubber composites has been concerned with the interactions between silica particles and the interactions between silica particles and rubber molecules. Wolff and Wang studied the effects of surface energies of fillers on rubber reinforcement, and reported ${ }^{7}$ that the surface energies of silica were characterized by a dispersive and specific components. The higher specific component led to the higher viscosity of the rubber composites due to the strong interactions among silica particles. On the other hand, the lower dispersive component caused weak filler-rubber interactions, leading to the lower

${ }^{\dagger}$ To whom correspondence should be addressed. content of bound rubber in the composites. Sawanobori et al. studied ${ }^{9}$ the effects of silanol group on the agglomerate of silica particles and the content of bound rubber in the silica filled polyisoprene. They found that the averaged size of agglomerate in the rubber matrix increased with the increase in the silanol number per unit surface area $(N)$ of silica particles, resulting in the increase of bound rubber content in the composite. Further, no trace of bound rubber was found in the composite which was prepared from silicas with low number of $N\left[N<0.1\left(\mathrm{~nm}^{-2}\right)\right]$. High-resolution solid state nuclear magnetic resonance (NMR) results of silica filled polyisoprene composites reported by Ono et al. ${ }^{10}$ showed no direct chemical bonding between silanol groups and rubber molecules. These results suggest that the formation of bound rubber is closely related to the development of agglomerate of silica particles in the rubber matrix and that the formation mechanism of bound rubber in the silica filled rubber composite cannot be explained simply by the dispersive component of filler as suggested by Wolff and Wang. ${ }^{7}$ As mentioned above, it is recognized that the agglomerate of silicas is primarily formed by the interactions such as van der WaalsLondon attractions and hydrogen bonding. Thus, it is 
possible to consider that the agglomerate in the rubber matrix might be easily destroyed by a mechanical stress. Transmission electron microscopy (TEM) observations for the samples prepared under different mechanical stress might give us a direct evidence for the destruction of agglomerate by the mechanical stress.

By the introduction of silane coupling agent, the disadvantage of silica as a filler is able to be reduced. For example, silica filled passenger tire compound shows a low hysterisis in comparison with a carbon black filled tire compound by the introduction of silane coupling agent, such as bis(3-triethoxysilylpropyl)tetrasulfane (TESPT) ${ }^{11-13}$ Some factors might be responsible for the properties achieved. The triethoxysilyl group of the TESPT reacts with the silanol groups of the silica during mixing compound with a loss of ethanol, ${ }^{11,12}$ which would cause the decrease of the specific component, leading to the decrease of interactions between silica particles. ${ }^{7}$ On the other hand, the rubber-reactive group of the silane has a strong tendency to form rubber-tofiller bonds during curing of the rubber compound. ${ }^{11,12}$

In this study, the mechanical properties of silica filled styrene-butadiene rubber (SBR) systems were studied in relation to the agglomerate of silica particles which can be controlled by the surface chemistry of silica and to the rubber-filler interactions which can be controlled by the introduction of bifunctional organosilane in the composites.

\section{EXPERIMENTAL}

\section{Samples}

Materials. The raw rubber used was an emulsion type styrene-butadiene rubber (SBR, Nipol SBR 1502, $\left.M_{\mathrm{w}}=430000\right)$. Fillers used were a precipitate silica (Nipsil AQ:AQ) and a fumed silica (Aerosil50:A-50). A HAF carbon black (N326) was also used as a reference. Characteristics of the fillers are listed in Table I. Two kinds of coupling agents (bis(3-triethoxysilylpropyl)tetrasulfane $<$ TESPT $>$ as a bifunctional organosilane and trimethoxymethyl silane $<$ MS $>$ as a monofunctional organosilane) were also used. The composites were prepared by a mechanical and a solution mixtures.

Mechanical Mixture. As shown in Table II, the mechanical mixture was prepared in three stages by using an internal mixer (Laboplastomill, Toyo Seiki Seisakushyo, LTD). In the first stage, the masterbatch (composite) was obtained by mixing the raw rubber with silica, and coupling agent if necessary. In the second stage, the masterbatch was mixed with the ingredients except sulfur and curing accelerator. In the third stage, the masterbatch obtained at the second stage was mixed
Table I. Characteristics of fillers

\begin{tabular}{|c|c|c|}
\hline & AQ & A-50 \\
\hline Diameter/nm & 18 & 50 \\
\hline Surface Area $/ \mathrm{m}^{2} \mathrm{~g}^{-1}$ & 187 & 50 \\
\hline $\mathrm{SiOH} / \mathrm{mmol} \mathrm{g}^{-1}$ & 1.86 & 0.24 \\
\hline$N / \mathrm{nm}^{-2}$ & 6.0 & 2.9 \\
\hline \multicolumn{3}{|c|}{$\begin{array}{l}N\left(\mathrm{~nm}^{-2}\right)=\mathrm{SiOH}\left(\mathrm{mmol} \mathrm{g}^{-1}\right) / \text { Surface Area }\left(\mathrm{m}^{2} \mathrm{~g}^{-1}\right) \times \mathrm{Na} \text {, } \\
\mathrm{Na} \text { : Avogadoro Number. }\end{array}$} \\
\hline & \multicolumn{2}{|c|}{ HAF } \\
\hline Diameter/nm & \multicolumn{2}{|c|}{27} \\
\hline Surface area $/ \mathrm{m}^{2} \mathrm{~g}^{-1}$ & \multicolumn{2}{|c|}{83} \\
\hline $24 \mathrm{M} 4 \mathrm{DBP} / \mathrm{mL} / 100 \mathrm{~g}^{\mathrm{a}}$ & \multicolumn{2}{|c|}{74} \\
\hline
\end{tabular}

Table II. Compositions of filled SBR system

\begin{tabular}{|c|c|c|c|c|c|c|c|}
\hline \multirow{2}{*}{\multicolumn{8}{|c|}{$\begin{array}{l}\text { Sample No. } \\
\text { (First Step) }\end{array}$}} \\
\hline & & & & & & & \\
\hline SBR1502 & 100 & 100 & 100 & 100 & 100 & 100 & 100 \\
\hline Nipsil AQ & & 50 & & 50 & 50 & 50 & \\
\hline Aerosil 50 (A-50) & & & 50 & & & & \\
\hline HAF carbon black & & & & & & & 60 \\
\hline Sulfur & & & & & & 1.2 & \\
\hline TESPT $^{\mathrm{a}}$ & & & & & 5 & & \\
\hline $\begin{array}{l}\mathrm{MS}^{\mathrm{b}} \\
\text { (Second Step) }\end{array}$ & & & & 5 & & & \\
\hline First Master Batch & 100 & 150 & 150 & 160 & 160 & 160 & 150 \\
\hline Zinc oxide & 3 & 3 & 3 & 3 & 3 & 3 & 3 \\
\hline Stearic acide & 2 & 2 & 2 & 2 & 2 & 2 & 2 \\
\hline $\begin{array}{l}\text { Anti-oxidant } 6 \mathrm{C}^{\mathrm{c}} \\
\text { (Third Step) }\end{array}$ & 1 & 1 & 1 & 1 & 1 & 1 & 1 \\
\hline Second Master Batch & 106 & 156 & 156 & 166 & 166 & 166 & 156 \\
\hline Accelerator $\mathrm{CZ}^{\mathrm{d}}$ & 1 & 1 & 1 & 1 & 1 & 1 & 1 \\
\hline Accelerator $\mathrm{DPG}^{\mathrm{e}}$ & 1.5 & 1.5 & 1.5 & 1.5 & 1.5 & 1.5 & \\
\hline Sulfur & 1.7 & 1.7 & 1.7 & 1.7 & 1.7 & 1.7 & 1.7 \\
\hline
\end{tabular}

with sulfur and curing accelerator. The final stock was seated on a roll mill followed by a vulcanization at $160^{\circ} \mathrm{C}$ for $30 \mathrm{~min}$ under a pressure.

Preparation of Bound Rubber. About $1 \mathrm{~g}$ of the unvulcanized mixture (the masterbatch at the first stage) that was cut into small pieces was loosely packed in a cage with 200 mesh size. The cage was immersed in a sufficiently large amount of toluene (about $300 \mathrm{~cm}^{3}$ ) at room temperature for $72 \mathrm{~h}$ to remove toluene soluble rubber. (There was no indication of leaching out of silica during the extraction.) The insoluble rubber component including silica "bound rubber" so-called was suspended in acetone to exchange the toluene with more volatile chemicals and filtered. The bound rubber was dried at room temperature for 3 days under a reduced 
pressure.

Sample Preparation for TEM Observation. The samples for transmission electron microscopy (TEM) observations were prepared from both the filled unvulcanized composite by solution mixture and the filled vulcanizates by mechanical mixture.

About $0.001 \mathrm{~g}$ of AQ was dispersed in $20 \mathrm{~mL}$ of benzene under a supersonicwave for $10 \mathrm{~h}$. The solution of SBR in benzene $(0.001 \mathrm{wt} \%)$ was mixed with the suspension of AQ in benzene, and coupling agent if necessary, with magnetic stirrer at room temperature for $3 \mathrm{~h}$. The ratio of SBR to silica was 2 and that of silica to coupling agent was 5 by weight. The mixed solution was dropped on the copper mesh coated by carbon for TEM observation. The composite was obtained by removing benzene from the mixed solution at $30^{\circ} \mathrm{C}$ under a reduced pressure of $1.5 \times 10^{-2}$ torr. The composite on the mesh was immersed in a sufficiently large amount of toluene after it was heated under the reduced pressure at $100^{\circ} \mathrm{C}$ for $10 \mathrm{~min}$ and extraction of free rubber was carried out at room temperature for $72 \mathrm{~h}$. The remain on the mesh was the bound rubber and silica.

The ultra-thin samples ( $c a$. 80-110 nm thick) were obtained by a microtoming of the hardened vulcanizate which was obtained by dipping the vulcanizate into sulfur at $120^{\circ} \mathrm{C}$ for $36 \mathrm{~h}$. The hardening was carried out under the different strain applied to the vulcanizates. The uptake of sulfur was about $0.55 \mathrm{~g}$ per $1 \mathrm{~g}$ of rubber determined from element (sulfur/carbon) analyzer (EMIA-510, Horiba, LTD). The hardened stretched samples were microtomed in parallel direction to the drawn direction.

\section{Measurements}

Amount of Bound Rubber. The amount of bound rubber $(\mathrm{Gt} ; \mathrm{g} / \mathrm{g})$ was determined as a mass of insoluble rubber per $1 \mathrm{~g}$ of silica. It was determined from the percentage of weight loss up to $650^{\circ} \mathrm{C}$ by a thermal gravimetric analyzer (TGA,TG/DTA220, Seiko Instruments).

${ }^{1}$ H Wide-Line Pulsed NMR. Pulsed nuclear magnetic resonance (NMR) measurements were carried out with a JEOL pulsed NMR spectrometer (JNM Mu 25), operating at $25 \mathrm{MHz}$. The solid echo sequence provided a good approximation to the free induction decay (FID), from which the proton spin-spin relaxation time $\left(T_{2}\right)$ was obtained. In this study, the width of $90^{\circ}$ pulse and the pulse interval were adjusted to be 2 and $10 \mu \mathrm{s}$, respectively. Details of NMR measurements were described in our earlier articles. ${ }^{14-17}$ Protons in both SBR and silica contributed to the NMR signals. Thus, the signals from silica were subtracted from observed signals to make a quantitative analysis of relaxation times

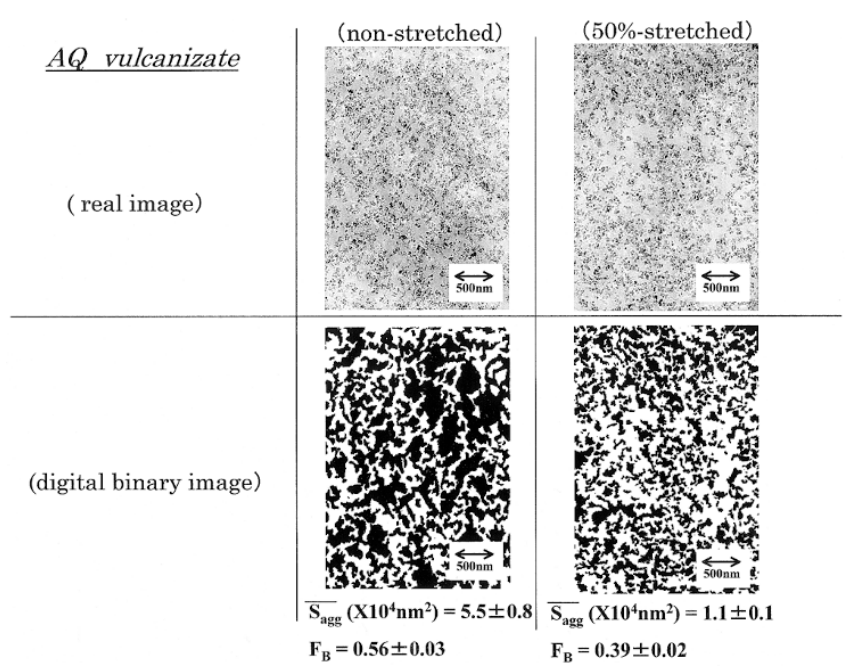

Figure 1. TEM images and digital binary images of non stretched and 50\% stretched AQ filled SBR vulcanizate.

of rubber molecules only.

Transmission Electron Microscopy (TEM) Observation. TEM observations were carried out by using a HITACHI H-9000 NAR Type at the accelerated voltage of $200 \mathrm{kV}$. A quantitative analysis was carried out for the TEM images by the conversion of observed TEM pictures to the digital binary images. Highly contrasted pictures were obtained from the observed TEM images. Then the digital binary images were prepared from the pictures by a personal computer. The details were described in our previous paper. ${ }^{18}$

Stress-Strain Behavior. The stress-strain curves were obtained by the tensile tester (Autograph, Shimadzu Seisaku-shyo, LTD) at room temperature with the strain rate of $100 \% \mathrm{~min}^{-1}$. The length of the samples was $5 \mathrm{~cm}$.

Dynamic Storage Modulus $\left(G^{\prime}\right)$. The dynamic storage modulus $\left(G^{\prime}\right)$ was determined by a dynamic viscoelastometer (Rheometrics Dynamic Spectrometer II, Rheometrics, Inc.) at $25^{\circ} \mathrm{C}$ under the constant torsion (shear) of \pm 0.2 to $\pm 10.0 \%$, and frequency of $1 \mathrm{~Hz}$.

\section{RESULTS AND DISCUSSION}

\section{Structural Change of Agglomerate by a Strain in Silica Filled Vulcanizates}

Figures 1 and 2 show typical TEM images and the digital binary images (DBI) converted from TEM images for non stretched and 50\% stretched ultra-thin films of filled vulcanizates which were prepared from AQ (Sample No. 2) and A-50 (Sample No. 3) by the mechanical mixture. The area fraction of black colored portion (silica phase) of the picture $\left(F_{\mathrm{B}}\right)$ and the averaged sizes of agglomerate of silica particles $\left(\bar{S}_{\text {agg }}\right)$ calculated from the DBI are shown at the bottom of each DBI. As seen in Figure 1, the agglomerates formed by 
$\underline{\text { A-50 vulcanizate }}$

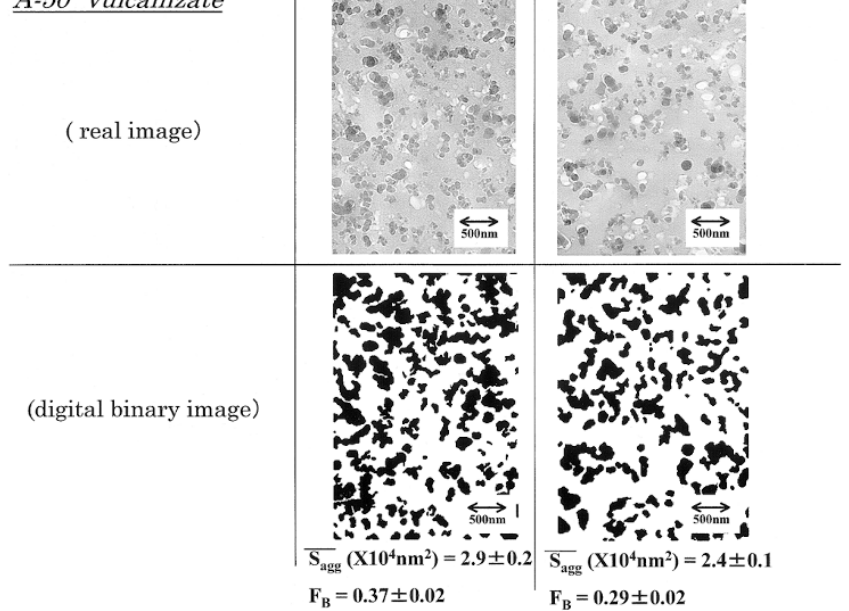

Figure 2. TEM images and digital binary images of non stretched and 50\% stretched A-50 filled SBR vulcanizate.

AQ silica particles were markedly broken down and the $\left(\bar{S}_{\text {agg }}\right)$ and $F_{\mathrm{B}}$ were also decreased by the $50 \%$ strain. On the other hand, the agglomerates formed by A-50 were slightly broken down, and the changes of $\left(\bar{S}_{\text {agg }}\right)$ and $F_{\mathrm{B}}$ by the strain were not obvious.

The $\left(\bar{S}_{\text {agg }}\right)$ was dependent on the sort of silica. The $\left(\bar{S}_{\text {agg }}\right)$ by the AQ, which had a larger number of silanol group per unit surface area (See Table I), was larger than that for the sample from A-50. These findings are in agreement with the report by Sawanobori et al. ${ }^{9}$ that the averaged size of agglomerate formed by silica particles in polyisoprene rubber matrix increased with increasing the number of silanol group per unit surface area of silica particles.

The content of silica in all hardened samples was adjusted to have a similar value of $\sim 24 \%$ by weight. Thus, all samples should have a similar value of $F_{\mathrm{B}}$. Contrary to our expectation, the $F_{\mathrm{B}}$ increased with increasing the size of agglomerates. In this study, the observed TEM images were converted into the digital binary images as a two-dimensional information. However, TEM images actually involved three-dimensional information due to the sample thickness. Thus, there is a possibility that the observed $F_{\mathrm{B}}$ value is slightly larger than the calculated one, 0.26 , which was obtained under the assumption that all silica particles were sphere. As seen in Figure 1, the difference between $F_{\mathrm{B}}$ and calculated value (0.26) is larger for the sample which has larger agglomerate than the smaller one. Sawanobori et $a l .{ }^{9}$ reported that a certain amount of rubber molecules was entrapped in the agglomerates as a bound rubber in silica filled polyisoprene rubber systems. Further, the content of bound rubber increased with increasing the size of agglomerate. In this study, the amount of bound rubber (Gt) was also determined. The Gts

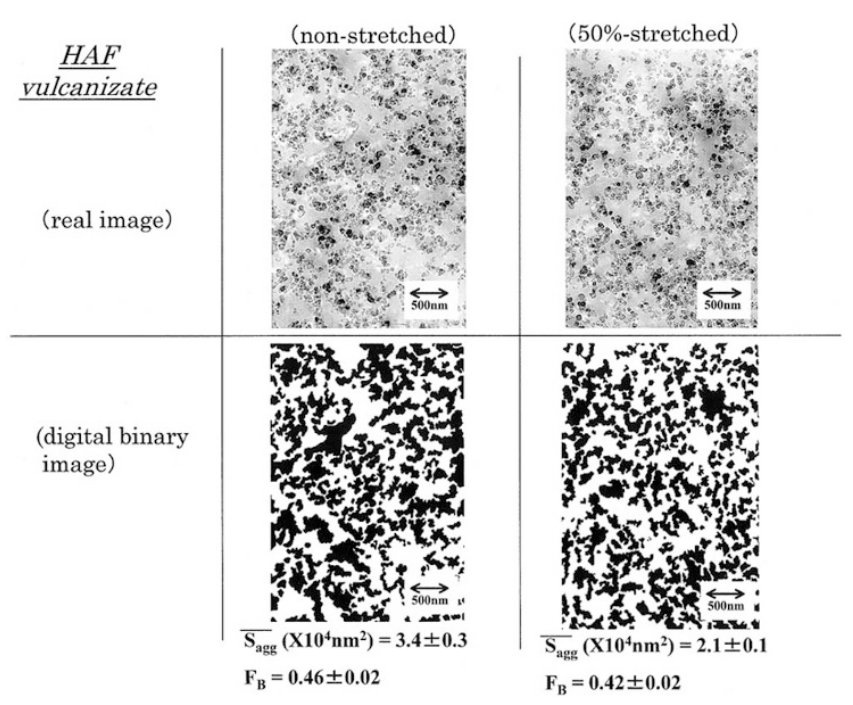

Figure 3. TEM images and digital binary images of non stretched and 50\% stretched HAF black filled SBR vulcanizate.

for AQ and A-50 filled composites were 0.65 and 0.47 $(\mathrm{g} / \mathrm{g})$, respectively. NMR results at $30^{\circ} \mathrm{C}$ for the bound rubber revealed that the spin-spin relaxation time $\left(T_{2}\right)$ for the highly mobile rubber phase was $314 \mu$ s for AQ filled composite and $373 \mu$ s for A-50 filled composite. These $T_{2} \mathrm{~S}$ were considerably short compared with that for pure SBR (about $800 \mu \mathrm{s}$ ). This means that the segmental mobility of bound rubber is highly constrained by silica particles.

These results suggest that the $F_{\mathrm{B}}$ value is also affected by the amount of bound rubber, which might be entrapped within the agglomerate. With increasing the size of agglomerate, the amount of bound rubber might increase, contributing to the increase of $F_{\mathrm{B}}$. The decrease of $F_{\mathrm{B}}$ by the strain implies that a part of the entrapped rubber molecules within the agglomerates is released by the breakdown of the agglomerates.

Figures 3 shows the typical TEM images and the digital binary images converted from TEM images for non stretched and the 50\% stretched ultra-thin films of black filled vulcanizates from HAF (Sample No. 7). The $\left(\bar{S}_{\text {agg }}\right)$ and the $F_{\mathrm{B}}$ were smaller than those of AQ filled vulcanizate due to the high dispersibility of carbon black in the rubber matrix. The structural changes by the $50 \%$ strain were not prominent compared with that of AQ filled vulcanizate. It is suggested that the bound rubber phase in the carbon black filled vulcanizates exists on the surface of carbon black. ${ }^{19}$ If so, the bound rubber phase is not necessarily released by the break down of agglomerate structure. In this case, $F_{\mathrm{B}}$ is not necessary to change by the strain. This consideration supports our speculation that the bound rubber in the silica filled vulcanizate corresponds to the entrapped rubber phase within the agglomerate. 


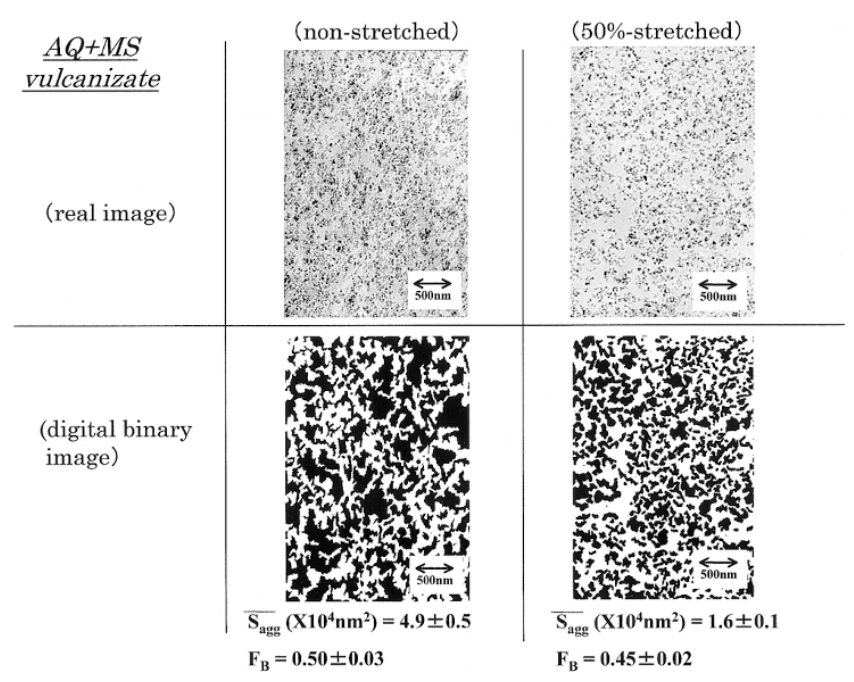

Figure 4. TEM images and digital binary images of non stretched and $50 \%$ stretched AQ filled SBR vulcanizate with the introduction of MS.

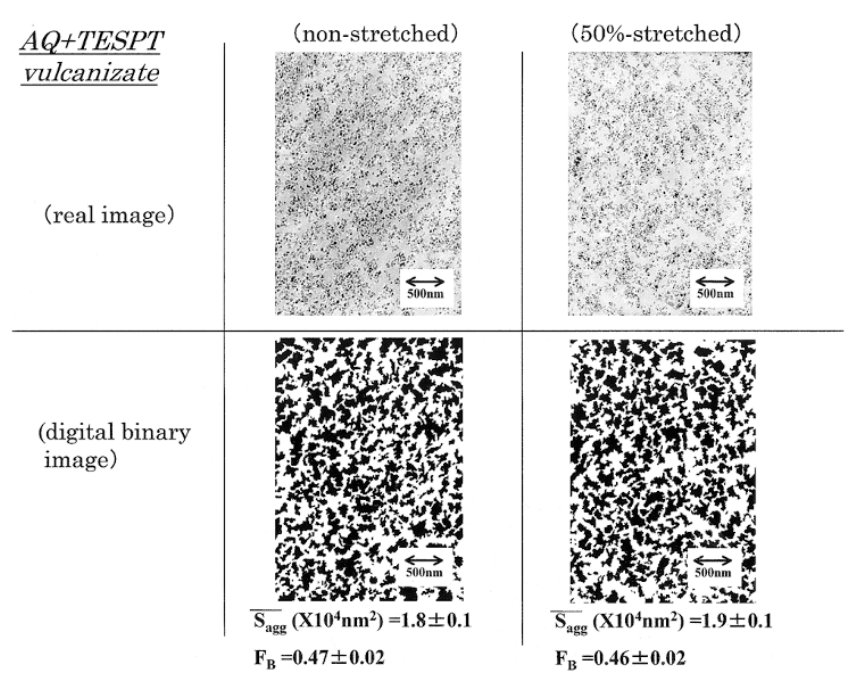

Figure 5. TEM images and digital binary images of non stretched and $50 \%$ stretched AQ filled SBR vulcanizate with the introduction of TESPT.

\section{Modification of Surface Chemistry of Silica by Cou- pling Agents}

Figures 4 and 5 show the typical TEM images and the digital binary images converted from TEM images for non stretched and the 50\% stretched ultra-thin films of filled vulcanizates from AQ with MS (Sample No. 4) and TESPT (Sample No. 5). The comparison of these figures with Figure 1 indicates that the $\bar{S}_{\text {agg }}$ and $F_{\mathrm{B}}$ were decreased by the introduction of coupling agent. Further, the structural changes by the $50 \%$ strain were not prominent. Moreover, the Gt for AQ filled composites with the introduction of coupling agent, MS, was $0.26(\mathrm{~g} / \mathrm{g})$, which was smaller than the sample without coupling agent. These results are quite different from those reported by Wolff et al. ${ }^{13}$ The decrease of Gt by the introduction of coupling agent might be related to the decrease of agglomerate size. The decrease of the

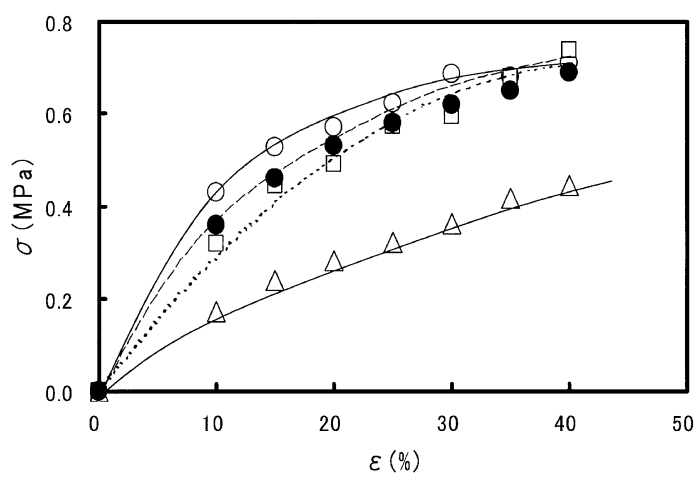

Figure 6. Stress-strain curves at room temperature for silica filled SBR vulcanizates (circle, open: AQ, circle, filled: AQ + MS, square, open: A-50, triangle, open: unfilled).

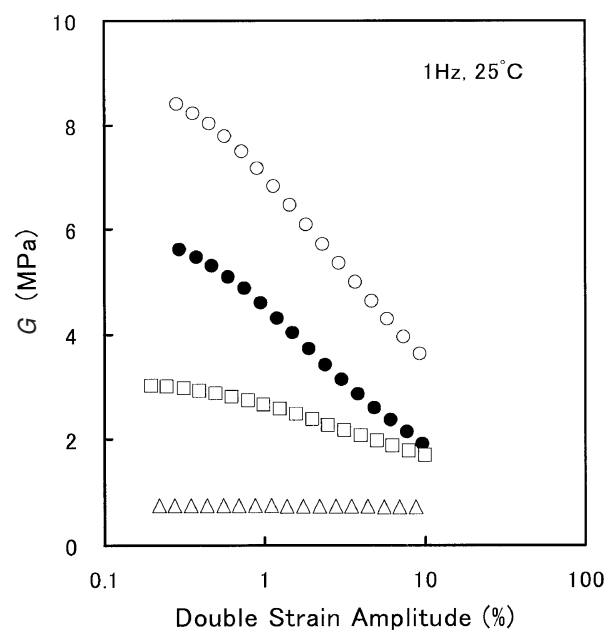

Figure 7. Strain dependence of $G^{\prime}$ for silica filled SBR vulcanizates (circle, open: AQ, circle, filled: $\mathrm{AQ}+\mathrm{MS}$, square, open: A-50, triangle, open: unfilled).

number of silanol group per unit surface area due to the reaction between silanol groups and alchoxy groups in coupling agents, induces the decrease of agglomerate size, resulted in the decrease of Gt as discussed above.

\section{Relationship between Agglomerate Size and Mechani- cal Properties in Silica Filled Rubber Systems}

Figure 6 shows the stress-strain curves of unfilled and silica filled vulcanizates (Sample No. 1-No. 4). The initial slopes of the curves decreased with decreasing the silanol number per unit surface area and the introduction of coupling agent, MS. The result suggests that the initial modulus of the samples decreases with the decrease in the agglomerate size of silica particles. Similar results were also found in the dynamic storage modulus, $G^{\prime}$ at the fine strain amplitude (See Figure 7). AQ filled vulcanizate showed a pseudo yielding point around $20 \%$ of strain. Around $40 \%$ of strain, all vulcanizates showed a similar stress, independent of sort of silica and the introduction of coupling agent. The yield phenomenon at a low strain has been thought to 


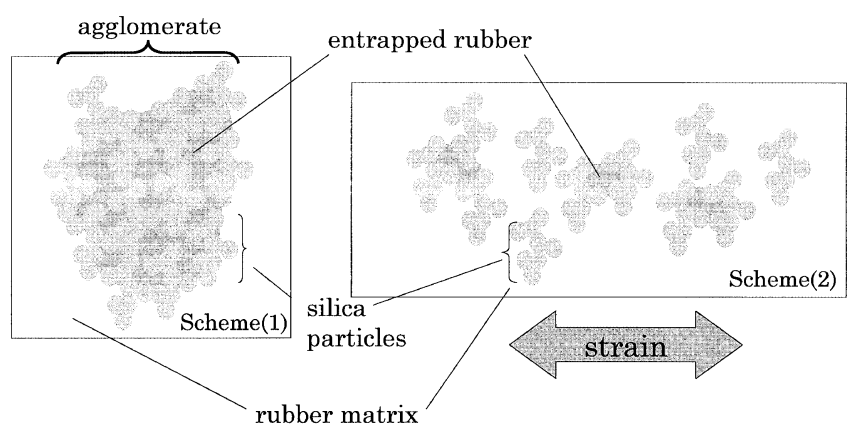

Figure 8. Schematic representation of the breakdown of agglomerates for silica filled SBR system (Scheme 1 : non stretched, Scheme 2 : stretched).

be the result of a breakdown of aggregates in the rubber matrix. ${ }^{1,2,20,21}$

Payne studied the effect of strain on the storage modulus for black filled vulanizate and reported 22,23 that the storage modulus of the vulcanizate decreased with increasing the strain amplitude with this tendency more prominent in the higher concentration of filler in the vulcanizate. Further, at a larger strain, the effects of filler concentration on the storage modulus became small. These results were explained by the breakdown of the aggregated network of filler particles or agglomerates formed by van der Waals-London attraction forces. This consideration was supported by Kraus. ${ }^{24}$

As stated before, the averaged size of agglomerate $\left(\bar{S}_{\text {agg }}\right)$ for AQ filled vulcanizate was decreased by the $50 \%$ strain in accordance with the prediction by Payne. ${ }^{22,23}$ An important result was that the area of silica phase in the vulcanizate $\left(F_{\mathrm{B}}\right)$ was also decreased by the $50 \%$ strain (See Figures 1, 2, and 3). The decrease was related to the release of entrapped rubber within the agglomerates.

Based on the results and discussion, the structural change of agglomerate by the strain is shown schematically in Figure 8. When the strain is applied to the filled vulcanizate, a breakdown of filler network occurs, which induces a decrease of agglomerate size, and simultaneously a part of the entrapped rubber within an agglomerate is released. Such released molecules migrate to the rubber matrix. Thus, the decrease of modulus with increasing the strain is arised from the breakdown of agglomerate of filler in the vulcanizate as suggested by Payne. ${ }^{22,23}$ This is reasonable because the filler networks between silica particles themselves acquire a higher elastic modulus due to the hydrogen bonding between silica particles, which is presumably stronger than van der Waals-London attractive interaction. Thus, the elasticity of the vulcanizate is decreased by the breakdown of the filler network.

The spin-spin relaxation time $\left(T_{2}\right)$ of unfilled vulcanizate (Sample No. 1) was about $500 \mu \mathrm{s}$, which
$\mathrm{AQ}+$ bound rubber

$\mathrm{AQ}+\mathrm{TESPT}+$ bound rubber
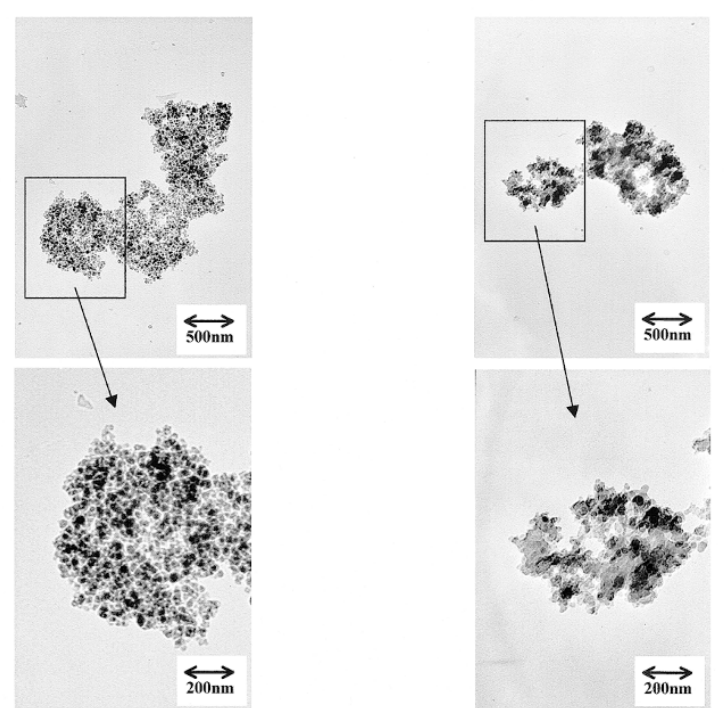

Figure 9. TEM images for silica particles and bound rubber from AQ filled SBR composites without and with the introduction of TESPT by solution mixture.

means that the segmental mobility of this sample is high. The filled vulcanizate involve agglomerates in which a certain amount of rubber is entrapped. The segmental mobility in the rubber matrix was similar to that of unfilled vulcanizate $\left(T_{2} \sim 500 \mu \mathrm{s}\right)$.

On the other hand, $T_{2}$ for the rubber molecules which were entrapped in the agglomerates was about $300 \mu \mathrm{s}$, which suggests that the segmental mobility of entrapped rubber molecules is highly constrained compared with that of rubber matrix. Thus, it is reasonable to speculate that the entrapped rubber phase is expected to show a higher elastic modulus compared with that of rubber matrix. By the release of entrapped rubber, the fraction of rubber phase with high elasticity in the filled vulcanizate decreases, leading to the decrease in modulus of the filled vulcanizate.

\section{Effects of Interfacial Combination of Fillers with Rub- ber Matrix on Mechanical Properties}

The inhomogeneous structure in silica filled rubber composite seems to be different from that of carbon black filled rubber composite. Kiuchi and Ito $^{19}$ found that the highly constrained rubber phase existed on filler surfaces of black filled composite. On the other hand, Sawanobori et al. reported ${ }^{9}$ that the constrained rubber phase existed only in the agglomerate of silica particles in the silica filled composites. These findings suggest that the mechanical properties of filled rubber systems are affected by the sort of fillers and the inhomogeneous structures, which are closely related to the polymer-filler interactions.

Figure 9 shows the typical TEM images for silica particles (AQ) and bound rubber without and with 


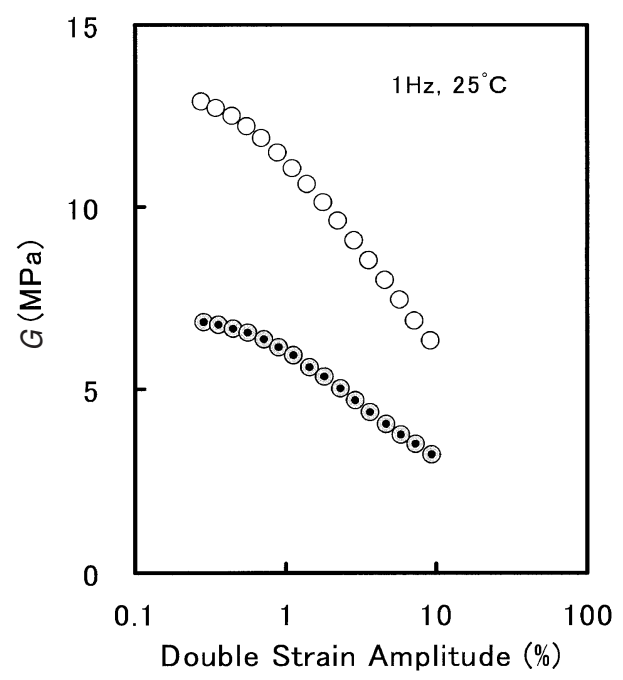

Figure 10. Strain dependence of $G^{\prime}$ for silica filled SBR vulcanizates (circle, open: AQ + Sulfur circle, dotted: AQ + TESPT).

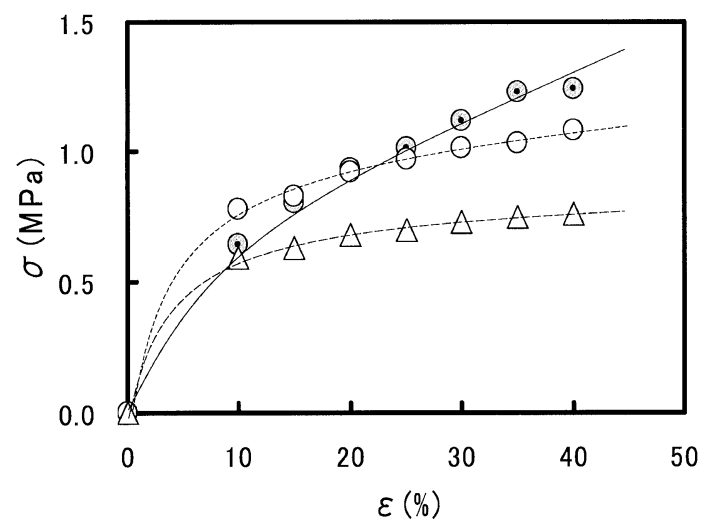

Figure 11. Stress-strain curves at room temperature for black and silica filled SBR vulcanizates (circle, open: AQ + Sulfur circle, dotted: AQ + TESPT triangle, open: AQ).

TESPT in the silica filled SBR composites prepared by solution mixture. For the composite without TESPT, no trace of bound rubber was found on the surface of silica. Bound rubber seemed to be within the agglomerate of silica particles. On the other hand, for the composite with TEPST, bound rubber phase remained on the surface of silica particles as was observed in carbon black filled rubber systems. ${ }^{19}$ The result indicates that the introduction of TEPST produces strong interactions between silica particles and rubber molecules.

Figure 10 shows the strain dependence on the storage modulus, $G^{\prime}$, of silica filled vulcanizates with and without TESPT (Sample No. 5 and 6). For two samples, the $G^{\prime}$ decreased with the increase in the strain amplitude, although the decrease became small by the introduction of TESPT. The decrease of modulus at the fine strain amplitude is related to the change of agglomerate size in the filled vulcanizate. Figure 11 shows the stress-strain curves of silica filled vulcanizates with and without TESPT (Sample No. 2, 5, and 6). The ini- tial slope of the stress-strain curve of silica filled vulcanizate was affected by the two factors; the one was the agglomerate size in the samples as discussed before, the other one was the degree of vulcanization. For the vulcanizates without TESPT, the slope increased with increasing the degree of vulcanization in accordance with the previous literatures. ${ }^{25,26}$ Important information obtained from the stress-strain curves was that the stress for the vulcanizates without TESPT almost leveled off above $20 \%$ strain. However, by the introduction of TESPT in the vulcanizate, the stress increased steadily with increasing the strain. Such an increase of stress with strain was also observed in the carbon black filled vulcanizates. ${ }^{2,7,13,21}$ As was discussed, the introduction of TESPT into the silica filled vulcanizate produced the interfacial bonding between silica and rubber matrix. A similar interfacial bonding has been suggested in the carbon black filled vulcanizates. ${ }^{19}$ The interfacial bonding between silica and rubber matrix might influence on the stress-strain behavior at a higher strain.

\section{CONCLUSIONS}

Mechanical tests and TEM observations were carried out for silica filled vulcanizates which were prepared from different kinds of silicas and the introduction of silane coupling agents. Following conclusions were derived from the experimental results.

1. The breakdown of secondary structure of silica particles was successfully detected by TEM observations when the strain was applied to silica filled vulcanizates.

2. TEM observations of silica filled vulcanizates which were imposed on the strain revealed that the degree of breakdown of agglomerate by the strain was more prominent in the larger agglomerates of which size was controlled by the silanol number per unit surface area of silica particles.

3. The amount of entrapped rubber within the agglomerate seemed to be decreased with the decrease in the agglomerate size. A part of the entrapped rubber might be released when the filler network was broken by the strain.

4. TEM observation of silica filled vulcanizates revealed that the initial agglomerate size and the change of agglomerate by the strain became small by the introduction of TESPT.

5. The initial modulus of silica filled vulcanizates was governed by the size of agglomerate formed by silica particles and the amount of entrapped rubber phase. On the other hand, with the introduction of interfacial combination between silica particles and rubber matrix by TESPT, the tensile strength of the filled vulcanizates in- 
creased. These results indicate that the stress-strain behavior of filled vulcanizate is influenced by the two factors. At a smaller strain, the agglomerate of the fillers has an important role on the stress-strain curve. At a larger strain, stress-strain curve is greatly affected by the interactions between filler and rubber matrix.

Acknowledgments. The authors would like to express appreciation to Dr. A. Ahagon for his valuable discussion through this work and to Dr. N. Miyashita for his helps for the TEM image analysis in The Yokohama Rubber Co., LTD. Special thanks are extended to The Yokohama Rubber Co., LTD for the permission to publish this paper.

\section{REFERENCES}

1. J. H. Bachmann, J. W. Shellers, M. P. Wagner, and R. F. Wolf, Rubber Chem. Technol., 32,1286 (1959).

2. M. P. Wagner, Rubber Chem. Technol., 47, 703 (1976).

3. W. H. Waddell, P. A. Beauregard, and L. R. Evans, Tire Technol. Int., p 24 (1995).

4. K. Ishikawa, F. Yatsuyanagi, and H. Kaido, presented at the 151st ACS Rubber Division Meeting, No. 9, Anaheim, California, May 6, 1997.

5. M. Hensel, K.-H. Menting, H. Umland, and C. Stone, Tire Technol. Int., 124 (1997).

6. K. Ishikawa, F. Yatsuyanagi, and H. Kaido, Rubber World, 218(5), 26 (1998).

7. S. Wolff and M.-J. Wang, Rubber. Chem. Technol., 65, 329 (1992).

8. S. Wolff, Rubber. Chem. Technol., 69, 325 (1996).

9. J. Sawanobori, S. Ono, and M. Ito, Kobunshi Ronbunshu, 57,
$356(2000)$.

10. S. Ono, Y. Kiuchi, J. Sawanobori, and M. Ito, Polym. Int., 48,1035 (1999).

11. U. Goerl, A. Hunsche, A. Mueller, and H. G. Koban, Rubber Chem. Technol., 70, 608 (1997).

12. S. A. Hunsche, U. Goerl, and M. Knaack, Kautsch. Gummi Kunstst., 50, 881 (1997).

13. S. Wolff, M.-J. Wang, and E.-H. Tan, Kautsch. Gummi Kunstst., 47, 102 (1994).

14. F. Yatsuyanagi, H. Kaidou, and M. Ito, Journal of the Society of Rubber Industry, Japan, 67, 707 (1994).

15. N. Kida, M. Ito, F. Yatsuyanagi, and H. Kaidou, J. Appl. Polym. Sci., 61, 1345 (1996).

16. F. Yatsuyanagi, H. Kaidou, N. Kida, and M. Ito, Journal of the Society of Rubber Industry, Japan, 70, 274 (1997).

17. F. Yatsuyanagi, H. Kaidou, and M. Ito, Rubber Chem. Technol., 72, 657 (1999).

18. F. Yatsuyanagi, N. Suzuki, M. Ito, and H. Kaidou, Polymer, 42, 9523 (2001).

19. Y. Kiuchi and M. Ito, Journal of the Society of Rubber Industry, Japan, 72, 599 (1999).

20. A. M. Bueche, J. Appl. Polym. Sci., 5, 271 (1961).

21. A. M. Bueche, 'Network Theory of Reinforcement' in "Reinforcement of Elastomers", G. Kraus, Ed., Interscience, New York, N.Y., 1965.

22. A. R. Payne, 'Dynamic Properties of Filler-Loaded Rubbers' in "Reinforcement of Elastomers", G. Kraus, Ed., Interscience, New York, N.Y., 1965.

23. A. R. Payne and R. E. Whittaker, Rubber Chem. Technol., 44, 440 (1971).

24. G. Kraus, J, Appl. Polym. Sci.: Applied Polymer Symposium, 39, 75 (1984).

25. W. Kuhn, Kolloid Z, 68, 2 (1934).

26. P. J. Flory, "Principles of Polymer Chemistry", Cornell University Press, New York, N.Y., 1953. 